\title{
A Convenient Truth: Cost of Medications Need Not Be a Barrier to Hepatitis B Treatment
}

Matthew Barnhart ${ }^{a}$

Drugs that are inexpensive to manufacture and simple to administer greatly expand the potential to help tens of millions of people who need treatment for chronic hepatitis B virus (HBV) infection. Key program implementation challenges include identifying who would benefit from antiviral medication and ensuring long-term and consistent treatment to people who feel well. The best opportunities are where health systems are advanced enough to effectively address these challenges and in settings where HIV service platforms can be leveraged. Research, innovation, and collaboration are critical to implement services most efficiently and to realize economies of scale to drive down costs of health care services, drugs, and diagnostics.

V iral hepatitis, principally due to chronic hepatitis B virus (HBV) and chronic hepatitis $\mathrm{C}$ virus (HCV), claimed 1.4 million lives worldwide in $2013,{ }^{1}$ a rising toll that is now actually greater than that of mortality from HIV. Of the annual deaths caused by viral hepatitis, almost half $(686,000)$ are attributable to HBV. ${ }^{1}$

Although HBV vaccination rates for the childhood routine hepatitis $\mathrm{B}$ vaccine series were $82 \%$ globally in $2014,{ }^{2}$ coverage rates for the hepatitis B birth dose-to optimally prevent mother-to-child (perinatal) transmission-lag behind. Furthermore, global disabilityadjusted life years lost due to HBV-associated liver cancer have continued to rise by $4.8 \%$ since $2005 .^{3}$ This is because the vast majority of complications from $\mathrm{HBV}$ occur among individuals older than 40 who were infected in the perinatal period or as young children. Indeed, an estimated 240 million individuals are already chronically infected, ${ }^{4}$ of whom $20 \%$ to $30 \%$ will eventually develop cirrhosis and/or liver cancer in the absence of treatment. ${ }^{5}$

Although chronic hepatitis B (CHB) infection is usually not curable, thankfully certain antiviral drugs are highly effective at suppressing viral replication and preventing the progress of liver damage without the development of resistance. A momentum is now building to expand access to these medications, in keeping with a new commitment within the Sustainable Development Goals to "combat hepatitis." ${ }^{6}$ In 2015, the World Health Organization (WHO) issued its

a Global Health, Science and Practice, Associate Editor, Washington, DC, USA.

Correspondence to Matthew Barnhart (mbarnhart@ghspjournal.org). first-ever recommendations for prevention, care, and treatment for persons with $\mathrm{CHB}^{5}$ and at the 2016 World Health Assembly a global health sector strategy on viral hepatitis was unanimously adopted ${ }^{7}$ that includes targets to treat 5 million people with $\mathrm{CHB}$ by 2020 and $80 \%$ of people in need by $2030 .^{8}$ While not all 240 million persons living with $\mathrm{CHB}$ need treatment, the number who would benefit from medication is enormous - 84 million people by one estimate. ${ }^{9}$

Considering that $\mathrm{CHB}$ treatment is lifelong in many cases, it might at first glance seem unaffordable to seek to expand treatment access to so many. But here is the convenient truth: $\mathrm{CHB}$ medications are simple to administer and potentially very inexpensive.

\section{LOW-COST HBV MEDICATIONS CAN CREATE NEW OPPORTUNITIES}

Unlike treatment for HIV or tuberculosis, in the substantial majority of $\mathrm{CHB}$ cases a single antiviral agent with a high barrier to resistance can effectively suppress HBV. WHO recommendations provide 2 options for preferred first-line agents, tenofovir disoproxil fumarate (TDF) or entecavir (ETV), ${ }^{5}$ and rates of virologic resistance are vanishingly low with either when used in treatment-naïve patients: $0 \%$ with longterm TDF $^{10}$ and $1.2 \%$ at 5 years with ETV. ${ }^{11}$ ETV and TDF both have a good safety and tolerability profile, although WHO recommends kidney function monitoring tests for people receiving either agent. ${ }^{5}$ Long-term TDF use has been associated with loss of bone mineral density, and ETV must be avoided in pregnant women due to evidence of harm in animal studies. 
TDF is already a backbone of HIV treatment at the same dosage approved for HBV treatment $(300 \mathrm{mg} /$ day) and had a ceiling price in 2015 of US $\$ 48$ per patient year as a generic for $\mathrm{HIV}^{12}$; that price would be quite affordable for $\mathrm{CHB}$ treatment in middle-income countries, although less than ideal for low-income countries. On the other hand, ETV requires a very low dose of $0.5 \mathrm{mg} /$ day (600-fold less than TDF), with an estimated cost of producing the active pharmaceutical ingredient (API) at scale of only US\$2-\$4 per year per a recent comprehensive analysis by Hill et al., ${ }^{13}$ which is one-sixth to one-twelfth the per-pill cost of API compared with TDF. Using quite conservative estimates, this analysis arrives at a price estimate of US\$36 per year for generic ETV. However, since the API cost per patient year for ETV should be about US\$20 less than TDF, it would also be reasonable to estimate that at high volumes the price of generic ETV could differ from the price of TDF by around US\$20. Thus, if WHO's 2030 goal of reaching $80 \%$ of people in need of $\mathrm{CHB}$ with treatment-over 50 million people-were met, the potential cost savings in using generic ETV rather than TDF might be close to US\$1 billion per year (although pregnant women and people living with HIV who were co-infected with HBV would still need to use TDF). ETV's low dose may also lower in-country logistic costs for transport and storage at sites.

\section{PATENT EXPIRATIONS WILL HELP}

While it is potentially very inexpensive to manufacture generic ETV, current prices of the drug are unfortunately very high, with a lowest global price of US $\$ 427$ for a generic version not approved by a stringent regulatory authority such as the U.S. Food and Drug Administration, and US\$6,127 for a generic version sold in the United States. ${ }^{13}$ This is because use of entecavir is currently very low, due in part to the very high prices of branded ETV and TDF, which have to some degree limited the uptake of these drugs in middle- and high-income countries (2015 originator prices in the United States were US\$15,111 for ETV and US\$10,718 for TDF). ${ }^{13}$ However, patents on ETV have recently expired in much of the world, including in the United States, and TDF's main patents will have expired by 2018 in most countries. This will create a dramatically different situation, as it should enable patients throughout the world to receive the most effective treatments while also making it economically feasible to explore the provision of treatment The toll of viral earlier in infection using a simplified public hepatitis is now health approach.

\section{PRIORITIZING RECIPIENTS} greater than that of mortality from HIV.

WHO's guidance appropriately recommends that treatment be prioritized first for patients who have cirrhosis. To prevent HBV-associated liver cancer and cirrhosis, however, it will be crucial to treat people before they develop cirrhosis, ${ }^{14}$ since liver inflammation occurring over many years predisposes to cancer development and end-stage liver disease. To identify patients without cirrhosis who are at high long-term risk of liver cancer, WHO recommends primarily using quantitative HBV DNA (viral load, or VL) testing, ${ }^{5}$ the key biomarker shown to correlate most closely with future risk. ${ }^{15}$ However, as HBV DNA VL testing may not be available in the near term in many low-resource settings due to cost and implementation constraints, WHO recommendations also allow for treatment of individuals over age 30 who have persistent elevations of liver enzymes (a conditional recommendation with a low quality of evidence). ${ }^{5}$ More research is needed to characterize easy-to-assess $\mathrm{CHB}$ prognostic factors for the development of HBV-related cirrhosis and liver cancer, including the relative benefits of treatment in preventing liver cancer in different disease stages, epidemiologic settings, and populations. This includes in sub-Saharan Africa, a region of the world where there is a dearth of robust prospective data despite having high prevalence overall and extremely high prevalence in many countries-for example $22 \%$ in South Sudan and $14 \%$ in Zimbabwe. ${ }^{4}$

\section{KEY CHALLENGES: TESTING, TREATMENT ELIGIBILITY, AND RETENTION}

Despite the low costs and clear benefits of antivirals, drugs will not be a magic bullet in and of themselves. To begin with, the proportion of people who have been tested for HBV is very low in most countries; WHO estimates that globally less than $5 \%$ of people living with chronic HBV and/or HCV are aware of their status. ${ }^{8}$ On a more positive note, even a one-time HBV test for adults could enable the identification of most people who would benefit from treatment, because the vast majority of HBV-associated liver cancer and cirrhosis occurs among people who were infected perinatally or as children. Rapid,

\section{WHO-issued targets aim to reach $80 \%$ of people with chronic hepatitis B in need of treatment by 2030.}

In most cases of chronic hepatitis B infection, a single antiviral agent with a high barrier to resistance can effectively suppress the virus.

\section{The proportion of people tested for $\mathrm{HBV}$ is very low in most countries, but rapid point-of-care tests could help.}


point-of-care tests have been developed for $\mathrm{HBV}^{16}$ and could boost efficiencies. However, the majority of rapid tests have not yet been prequalified by WHO, and multiple tests lack international validation of sensitivity and specificity in the populations in which they might be used.

Beyond testing, other substantial implementation challenges include linkage to longitudinal care services and differentiating between patients qualifying for treatment now versus those who only need regular monitoring. In addition to providing drugs for long-term daily intake, programs will also need to convince people who feel healthy to adhere to long-term medication. While this is a challenge common to many chronic diseases, it is very salient for HBV, since only a minority of people living with chronic infection will die from its consequences, which often occur several decades after diagnosis.

To enable optimal access to low-cost HBV drugs and laboratory tests, countries will benefit from working together to achieve economies of scale.

\section{Significant programmatic synergies with HIV platforms exist, which could help enable hepatitis B treatment programs in countries with less advanced health systems.} Engaging and retaining men into long-term treatment is also critical for CHB treatment programs, particularly because men have a more than threefold higher risk for HBV-associated liver cancer than women $(27 \%$ vs. $8 \%$ lifetime risk, respectively, among those infected in the perinatal period). ${ }^{17}$ Retention of patients on antivirals is important not only to reduce risk of liver cancer and cirrhosis but also to avoid hepatic "flares"—serious and sometimes life-threatening increases in liver inflammation that can occur for several reasons among people living with HBV, including due to an immune response to virus when it resurges after medications are stopped. ${ }^{18}$

\section{LEVERAGING HIV PLATFORMS}

Scaling up any new service entails significant organizational effort and cost. In light of these various hurdles, the best opportunities to expand CHB treatment rapidly may occur where health systems are relatively advanced, for example, in middle-income countries in Asia that have a high HBV burden. However, significant programmatic synergies with HIV platforms also exist, which could help enable service delivery even in low-income countries with less robust health systems, including many in sub-Saharan Africa that have extensive HIV treatment programs. Supply chain, laboratory testing, and longitudinal care systems for HIV treatment have great commonality with HBV treatment. Even for more complex elements of HBV care such as viral load testing, promising opportunities exist to leverage existing HIV infrastructure, as easy-to-transport dried-blood spots that are used for HIV DNA-PCR testing can also be used to quantify HBV DNA ${ }^{19}$ and test Hepatitis B e antigen ( $\mathrm{HBeAg}),{ }^{20} 2$ strong markers of risk for developing liver cancer. HBV treatment programs can also draw on lessons from community outreach, peer support, and service delivery models that HIV programs have developed, including approaches to increase male engagement and to support adherence and retention.

\section{COLLABORATION, INNOVATION, AND RESEARCH}

Most countries with high burdens of HBV have growing economies that can mobilize their own domestic resources to support the increased costs of expanding $\mathrm{CHB}$ treatment, which ultimately may save costs by reducing long-term medical expenses for liver cancer and cirrhosis. But to enable optimal access to generic ETV and the variety of HBV-related laboratory tests that will be needed, countries will benefit from actively working together to achieve greater economies of scale, using approaches such as coordinated ordering and prequalification of products to address regulatory bottlenecks. New technologies will also be important to drive down costs and improve outcomes. One such example is tenofovir alafenamide (TAF), a second-generation prodrug of tenofovir recently reported to be non-inferior to TDF in phase III trials of HBV treatment. ${ }^{21}$ TAF causes less bone and renal toxicity than TDF and should be less expensive, as it is effective at a low dose of $25 \mathrm{mg} /$ day, although as a patent-protected drug it may be very expensive for many countries. It is also quite possible that the dose of TDF needed to treat HBV effectively may be markedly less than for HIV, as in in vivo animal studies TDF produces about $50 \%$ of the levels of the active metabolites in liver cells compared with TAF on a per mg basis. ${ }^{22}$ This suggests that dose-reduction studies of TDF for CHB treatment may be an alternate avenue to explore to reduce cost and toxicity. Low-dose agents such as TAF, and especially ETV, might also be amenable to longacting implants, ${ }^{23}$ which, along with technology platforms such as mHealth, may improve longterm adherence. And research toward a cure for CHB remains important. ${ }^{24}$ Along with therapeutic advances, innovations in laboratory testing are needed, such as point-of-care liver function tests $^{25}$ and easier-to-use viral DNA assays. Lastly, and perhaps most importantly, the global health 
community should learn by doing together, collaborating on a technical level to develop optimal delivery models for specific contexts and conducting joint research to provide better information about which patients would benefit from $\mathrm{CHB}$ treatment. Given the universally low $\mathrm{CHB}$ treatment access that currently exists in low-, middle-, and high-income countries, many people throughout the world would be helped from such technical collaborative efforts done in a true spirit of global health partnership.

Competing Interests: None declared.

\section{REFERENCES}

1. GBD 2013 Mortality and Causes of Death Collaborators. Global, regional, and national age-sex specific all-cause and causespecific mortality for 240 causes of death, 1990-2013: a systematic analysis for the Global Burden of Disease Study 2013. Lancet. 2015;385(9963):117-171. CrossRef. Medline

2. Subaiya S, Dumolard L, Lydon P, Gacic-Dobo M, Eggers R, Conklin L. Global routine vaccination coverage, 2014. MMWR Morb Mortal Wkly Rep. 2015;64(44):1252-1255. CrossRef. Medline

3. GBD 2013 DALYs and HALE Collaborators; Murray CJ, Barber RM, Foreman KJ, Abbasoglu Ozgoren A, Abd-Allah F, Abera SF, et al. Global, regional, and national disability-adjusted life years (DALYs) for 306 diseases and injuries and healthy life expectancy (HALE) for 188 countries, 1990-2013: quantifying the epidemiological transition. Lancet. 2015;386(10009): 2145-2191. CrossRef. Medline

4. Schweitzer A, Horn J, Mikolajczyk RT, Krause G, OHt JJ. Estimations of worldwide prevalence of chronic hepatitis $B$ virus infection: a systematic review of data published between 1965 and 2013. Lancet. 2015;386(10003):1546-1555. CrossRef. Medline

5. World Health Organization (WHO). Guidelines for the prevention, care and treatment of persons with chronic hepatitis $B$ infection. Geneva: WHO; 2015. Available from: http://www. who.int/hiv/pub/hepatitis/hepatitis-b-guidelines/en/

6. Sustainable Development Knowledge Platform [Internet]. New York: United Nations Department of Economic and Social Affairs; c2016. Goal 3: ensure healthy lives and promote well-being for all at all ages; [cited 2016 May 1]. Available from: https://sustainabledevelopment.un.org/sdg3

7. World Hepatitis Alliance [Internet]. London (UK). World Hepatitis Alliance; 2016. Governments on track to eliminate viral hepatitis by 2030; 2016 May 28 [cited 2016 May 31]. Available from: http://www.worldhepatitisalliance.org/en/news/may-2016/ governments-track-eliminate-viral-hepatitis-2030

8. World Health Organization (WHO). Draft global health sector strategy on viral hepatitis, 2016-2021: the first of its kind draft. Geneva: WHO; 2015. Available from: http://who.int/hepatitis/ strategy2016-2021/Draft_global_health_sector_strategy_ viral_hepatitis_13nov.pdf

9. Hatzakis A. Moving the global agenda forward: what needs to happen at national and international levels? Presented at: WHO Global Partners' Meeting on Hepatitis; 2014 Mar 27-28; Geneva.
10. Kitrinos KM, Corsa A, Liu Y, Flaherty J, Snow-Lampart A Marcellin $\mathrm{P}$, et al. No detectable resistance to tenofovir disoproxil fumarate after 6 years of therapy in patients with chronic hepatitis B. Hepatology. 2014;59(2):434-442. CrossRef. Medline

11. Tenney DJ, Rose RE, Baldick CJ, Pokornowski KA, Eggers BJ, Fang J, et al. Long-term monitoring shows hepatitis $B$ virus resistance to entecavir in nucleoside-naiive patients is rare through 5 years of therapy. Hepatology. 2009;49(5): 1503-1514. CrossRef. Medline

12. Clinton Health Access Initiative (CHAI). 2015 antiretroviral (ARV) CHAl reference price list. Boston: CHAl; 2015. Available from: http://www.clintonhealthaccess.org/content/uploads/2016/ 01/2015-CHAl-ARV-Reference-Price-List.pdf

13. Hill A, Gotham D, Cooke G, Bhagani S, Andrieuz-Meyer I, Cohn J, et al. Analysis of minimum target prices for production of entecavir to treat hepatitis B in high- and low-income countries. J Virus Erad. 2015;1:103-110. Available from: http:// viruseradication.com/journal-details/Analysis_of_ minimum_target_prices_for_production_of_entecavir_to_treat_ hepatitis_B_in_high-_and_low-income_countries/

14. Zoulim F, Mason W. Reasons to consider earlier treatment of chronic HBV infections. Gut. 2012;61(3):333-336. CrossRef. Medline

15. Chen CJ, Yang HI, Su J, Jen CL, You SL, Lu SN, et al; REVEAL-HBV Study Group. Risk of hepatocellular carcinoma across a biological gradient of serum hepatitis B virus DNA level. JAMA. 2006;295(1):65-73. CrossRef. Medline

16. Franzeck FC, Ngwale R, Msongole B, Hamisi M, Abdul O, Henning L. Viral hepatitis and rapid diagnostic test based screening for $\mathrm{HBsAg}$ in HIV-infected patients in rural Tanzania. PLoS One. 2013;8(3):e58468. CrossRef. Medline

17. Huang YT, Jen CL, Yang HI, Lee MH, Su J, Lu SN, et al. Lifetime risk and sex difference of hepatocellular carcinoma among patients with chronic hepatitis B and C. J Clin Oncol. 2011; 29(27):3643-3650. CrossRef. Medline

18. Chang ML, Liaw YF. Hepatitis B flares in chronic hepatitis B: pathogenesis, natural course, and management. J Hepatol. 2014;61(6):1407-1417. CrossRef. Medline

19. Lira R, Maldonado-Rodriguez A, Rojas-Montes O, Ruiz-Tachiquin M, Torres-Ibarra R, Cano-Dominguez C, et al. Use of dried blood samples for monitoring hepatitis $B$ virus infection. Virol J. 2009;6:153. CrossRef. Medline

20. Mohamed S, Raimondo A, Pénaranda G, Camus C, Ouzan D, Ravet $S$, et al. Dried blood spot sampling for hepatitis $B$ virus serology and molecular testing. PLoS One. 2013;8(4):e61077. CrossRef. Medline

21. Gilead Sciences [Internet]. Foster City (CA): Gilead; c20092016. Gilead B announces top-line results from two phase 3 studies evaluating tenofovir alafenamide (taf) for patients with chronic hepatitis infection; 2016 Jan 5 [cited 2016 Feb 21] Available from: http://www.gilead.com/news/press-releases/ 2016/1/gilead-announces-topline-results-from-two-phase-3studies-evaluating-tenofovir-alafenamide-taf-for-patients-withchronic-hepatitis-b-infection

22. Murakami E, Wang T, Park Y, Hao J, Lepist El, Babusis D, et al. Implications of efficient hepatic delivery by tenofovir alafenamide (GS-7340) for hepatitis B virus therapy. Antimicrob Agents Chemother. 2015;59(6):3563-3569. CrossRef. Medline

23. Gunawardana M, Remedios-Chan M, Miller CS, Fanter R, Yang $F$, Marzinke MA, et al. Pharmacokinetics of long-acting tenofovir alafenamide (GS-7340) subdermal implant for HIV prophylaxis. Antimicrob Agents Chemother. 2015;59(7): 3913-3919. CrossRef. Medline 
24. Liang TJ, Block TM, McMahon BJ, Ghany MG, Urban S, et al. Present and future therapies of hepatitis $B$ : from discovery to cure. Hepatology. 2015;62(6):1893-908.

CrossRef. Medline
25. Pollock NR, Rolland JP, Kumar S, Beattie PD, Jain S, Noubary F, et al. A paper-based multiplexed transaminase test for low-cost, point-of-care liver function testing. Sci Transl Med. 2012; 4(152):152ra129. CrossRef. Medline

First Published Online: 2016 Jun 16

Cite this article as: Barnhart $M$. A convenient truth: cost of medications need not be a barrier to hepatitis B treatment. Glob Health Sci Pract. 2016;4(2):186-190. http://dx.doi.org/10.9745/GHSP-D-16-00128

(c) Barnhart. This is an open-access article distributed under the terms of the Creative Commons Attribution License, which permits unrestricted use, distribution, and reproduction in any medium, provided the original author and source are properly cited. To view a copy of the license, visit http://creativecommons.org/licenses/by/3.0/. When linking to this article, please use the following permanent link: http://dx.doi.org/10.9745/GHSP-D-16-00128. 